\title{
Oculus Rift Headset
}

National Cancer Institute

\section{Source}

National Cancer Institute. Oculus Rift Headset. NCI Thesaurus. Code C150358.

A proprietary virtual reality headset. 